\title{
Covered and uncovered biliary metal stents provide similar relief of biliary obstruction during neoadjuvant therapy in pancreatic cancer: a randomized trial
}

\section{Short Title: Biliary metal stents in neoadjuvant therapy}

Dong Wan Seo ${ }^{1}$; Stuart Sherman ${ }^{2}$; Kulwinder S. Dua ${ }^{3}$; Adam Slivka ${ }^{4}$; Andre Roy ${ }^{5}$; Guido Costamagna $^{6}$; Jacques Deviere ${ }^{7}$ Joyce Peetermans ${ }^{8}$; Matthew Rousseau ${ }^{8}$; Yousuke Nakai ${ }^{9}$; Hiroyuki Isayama" ${ }^{9 *}$, and Richard Kozarek ${ }^{10}$ for the "Biliary SEMS during neoadjuvant therapy study group"

\section{Authors' affiliations:}

1. Internal Medicine, Asan Medical Center University of Ulsan, Seoul, South Korea

2. Division of Gastroenterology and Hepatology Indiana University School of Medicine, Indianapolis, Indiana, United States

3. Gastroenterology and Hepatology, Medical College of Wisconsin, Milwaukee, Wisconsin, United States

4. Gastroenterology, Hepatology and Nutrition, University of Pittsburgh Medical Center, Pittsburgh, Pennsylvania, United States

5. Surgery, Centre hospitalier de l'Université de Montréal, Montreal, Quebec, Canada

6. Fondazione Policlinico A. Gemelli - IRCCS, Digestive Endoscopy Unit, Roma, Italy; Università Cattolica del S. Cuore, Roma, Italy

7. Gastro-Entérologie et d'Hépato-Pancréatologie, Universite Libre de Bruxelles Hôpital Erasme, Brussels, Belgium

8. Boston Scientific Corporation, Marlboro, Massachusetts, United States

9. Gastroenterology, University of Tokyo, Tokyo, Japan*

10. Digestive Disease Institute, Virginia Mason Medical Center, Seattle, Washington, United States

* Current institutional affiliation for Hiroyuki Isayama is Graduate School of Medicine, Juntendo University, Tokyo, Japan

This is the author's manuscript of the article published in final edited form as:

Seo, D. W., Sherman, S., Dua, K. S., Slivka, A., Roy, A., Costamagna, G., ... Kozarek, R. (2019). Covered and uncovered biliary metal stents provide similar relief of biliary obstruction during neoadjuvant therapy in pancreatic cancer: A randomized trial. Gastrointestinal Endoscopy. https://doi.org/10.1016/j.gie.2019.06.032 
Word Count: 3,818

\section{Corresponding authors' contact information:}

Please note there are two corresponding authors:

Dr. Richard Kozarek

Virginia Mason Medical Center

1100 Ninth Ave.

Seattle, WA 98101

Richard.Kozarek@virginiamason.org

Tel: +1-206-399-6716 Fax: +1-206-341-0180

Professor Dong Wan Seo, M.D.

Department of Gastroenterology, Asan Medical Center, University of Ulsan College of Medicine

388-1 Pungnapdong, Songpagu, Seoul, Korea Zip code: 05505

Tel: +82 230103190 Fax: +82-2-485-5782

email: $\underline{\text { dwseoamc@amc.seoul.kr }}$ 
A randomized comparison of covered versus uncovered biliary metal stents during neoadjuvant therapy in pancreatic cancer

\section{Short Title: Biliary Metal Stents in Neoadjuvant Therapy}

Dong Wan Seo1; Stuart Sherman2; Kulwinder S. Dua3; Adam Slivka4; Andre Roy5; Guido Costamagna6; Jacques Deviere7; Joyce Peetermans8; Matthew Rousseau8; Yousuke Nakai9; Hiroyuki Isayama9*, and Richard Kozarek10 for the "Biliary SEMS during neoadjuvant therapy study group" 


\section{Abstract}

Background and Aims: Preoperative biliary drainage with self-expanding metal stents (SEMSs) brings liver function within acceptable range in preparation for neoadjuvant therapy (NATx) and provides relief of obstructive symptoms in patients with pancreatic cancer. We compared fully covered SEMSs (FCSEMSs) and uncovered SEMSs (UCSEMSs) for sustained biliary drainage before and during NATx.

Methods: Patients with pancreatic cancer and planned NATx needing treatment of jaundice and/or cholestasis before pancreaticoduodenectomy were randomized to FCSEMS versus UCSEMS. Primary endpoint was sustained biliary drainage, defined as absence of reinterventions for biliary obstructive symptoms, and was assessed from SEMS placement until curative intent surgery (CIS) or 1 year.

Results: The intent-to-treat population had 119 patients (59 FCSEMS, 60 UCSEMS). Sustained biliary drainage was equally successful with FCSEMS and UCSEMS (72.2\% vs 72.9\%, noninferiority $\mathrm{P}=0.01$ ). Reasons for FCSEMS and UCSEMS failure differed significantly between groups and included tumor ingrowth in 0 versus $16.7 \%, \mathrm{P}<0.01$, and stent migration in $6.8 \%$ vs. $0, \mathrm{P}=0.03$, respectively. Serious adverse event rates related to stent placement were insignificantly different in both groups $(23.7 \%(14 / 59)$ vs $20.0 \%(12 / 60), \mathrm{P}=0.66)$, as were acute cholecystitis rates when gallbladder in situ (9.3\% (4/43) vs 4.8\% (2/42), $\mathrm{P}=0.68)$ for FCSEMSs and UCSEMSs, respectively. In our study, independent of stent type, predictors of reinterventions were $4 \mathrm{~cm}$ stent length and presence of gallbladder.

Conclusion: FCSEMSs and UCSEMSs provide similar preoperative management of biliary obstruction in pancreatic cancer patients receiving NATx, but mechanisms of stent dysfunction depend on stent type, stent length, and presence of the gallbladder.

Key Words: pancreatic cancer; biliary obstruction; fully covered self-expanding metal stents; uncovered self-expanding metal stents; neoadjuvant therapy; preoperative management.

Clinical Trial Registration: ClinicalTrials.gov NCT02238847 


\section{Introduction}

In the United States, pancreatic cancer is the second most common digestive cancer and the fourth leading cause of cancer death, with a 5-year survival rate of only 6\%.(1) Approximately $70 \%$ of patients with pancreatic cancer present with biliary obstruction,(2) and those with borderline resectable, locally advanced, or even resectable tumors often undergo preoperative neoadjuvant therapy (NATx) to downsize the tumor, provide early treatment of micrometastases, and ultimately optimize post-operative survival.(3-7) Preoperative biliary drainage mainly aims to resolve jaundice and bring elevated liver function tests (LFTs) within acceptable range so that NATx may be initiated, and maintain relief of biliary obstructive symptoms during NATx. $(8,9)$ The latter decreases the risk of inciting an inflammatory cascade in severely jaundiced patients,(10) and reduces the risk of adverse events from inadequate drainage, such as cholangitis.(11) Without effective preoperative drainage, patients may experience interruption of the NATx and/or delayed surgery.

Uncovered (UC) and fully covered (FC) self-expanding metal stents (SEMS) were shown to be superior to plastic stents for preoperative biliary drainage due to increased stent patency.(12-16) FCSEMSs were developed to prevent tissue ingrowth. Several meta-analyses assessed UCSEMSs versus FCSEMSs, and although most have shown no differences in stent patency or patient survival, conflicting results were reported for rates of SEMS migration, tumor ingrowth, tumor overgrowth, and acute cholecystitis.(17-22) Both FCSEMSs and UCSEMSs used in this study are cleared for palliative treatment of malignant biliary strictures and relief of biliary obstruction before surgery. The FCSEMS is also indicated for treatment of some benign biliary strictures. Thus, FCSEMS given their removable attribute, can offer on-label advantages in the setting of biliary strictures of indeterminate etiology. We sought to assess in a prospective randomized fashion whether this FCSEMS was noninferior to the UCSEMS for preoperative sustained biliary drainage in pancreatic cancer patients with planned NATx before curative intent pancreaticoduodenectomy. We deemed this study would lead to benefit in clinical practice if noninferiority of a FCSEMS was demonstrated. As such, if an FCSEMS was chosen because a biliary stricture was indeterminate, a subsequent diagnosis of underlying malignancy should not entail FCSEMS exchange for an UCSEMS (because of concern for stent migration or development of cystic duct obstruction and cholecystitis). Although the study was not powered 
to compare the rate of incidence of adverse events that are particularly feared in this immunosuppressed population, we documented adverse event rates carefully to rule out major differences between FCSEMS and UCSEMS groups.

\section{Methods}

\section{Design}

In this international, prospective, multicenter trial (ClinicalTrials.gov NCT02238847), we randomized patients in a 1:1 ratio to preoperative biliary drainage with a FCSEMS versus UCSEMS (WallFlex Biliary RX Fully Covered and Uncovered Stent, Boston Scientific, Marlborough, Mass). Block randomization was performed via an online database accessed on site at the start of the procedure. Randomization was stratified by study site. At each site concealed envelopes were used as the back-up randomization system.

Each participating institution's Ethics Committee/Institutional Review Board approved the study and each patient gave written informed consent. All authors had access to the study data and reviewed and approved the final manuscript.

The study stent system consists of a flexible delivery system preloaded with a radiopaque SEMS with flared ends. The FCSEMS is covered with a Permalume Coating (translucent silicone polymer) and has a retrieval loop for removal, neither features being contained in the UCSEMS. Selection of stent length and diameter were at the discretion of the Investigator.

\section{Patients and Procedures}

Patients with pancreatic cancer scheduled for NATx and needing preoperative biliary drainage before curative intent surgery (CIS) were screened for study eligibility. The location of the biliary stricture had to allow for the proximal end of the SEMS to be positioned at least $2 \mathrm{~cm}$ below the hilum to assure enough not previously stented bile duct for dissection and anastomosis during surgery. Patients were treated with NATx per local standard of medical oncology. Patients who proceeded to CIS were followed for 30 days post-surgery and their survival status was checked at 1 year. Patients who did not reach CIS proceeded to nonoperative, palliative care and were followed to 1 year after biliary SEMS placement. 


\section{Endpoints}

The primary endpoint was sustained biliary drainage, defined as absence of reinterventions for the management of biliary obstructive symptoms, assessed from SEMS placement until CIS when applicable or to one year after SEMS placement otherwise.

Secondary endpoints included technical success defined as ability to deploy the stent in a satisfactory position across the stricture, ability to complete NATx as intended without stentrelated interruptions of NATx and without biliary reintervention, subjective impression of the surgeon that the presence of a SEMS may have impacted the surgical procedure, and serious adverse events (SAEs) related to the stent and/or stent placement procedure, up to 30 days after surgery where applicable or 1 year after stent placement for patients not undergoing surgery. Adverse events (AEs) were predefined as detailed in Appendix 1. Also assessed were mortality at one year after randomization and incidence of stent migration, stent occlusion due to tumor ingrowth, and acute cholecystitis as causes for reintervention, and improvement of liver function tests (LFTs) until surgery for patients undergoing surgery and until 1 year after stent placement for patients not undergoing surgery.

\section{Statistical Methods}

Statistical testing was performed to determine if the rate of attaining sustained biliary drainage when using the FCSEMS was noninferior to the rate when using the UCSEMS. A noninferiority design was selected because preoperative biliary drainage was first described using UCSEMS, but there have been no RCTs to establish if FCSEMS are, in fact, noninferior. This question is relevant because there were reports that FCSEMS have a higher risk of stent migration and of causing acute cholecystitis when the cystic duct confluence is covered by the FCSEMS, whereas it was also reported that UCSEMS are associated with risk of occlusion due to tumor ingrowth.

A meta-analysis of 9 pertinent articles representing 377 patients,(13, 15, 23-29) yielded a success rate estimate of $84.6 \%$ (95\% confidence interval [CI], 80.5\%-87.9\%). Assuming the success rate of each arm was $80.5 \%$, a sample size of 102 patients would provide $80 \%$ power to reject the null hypothesis that FCSEMSs are inferior to UCSEMSs, using a noninferiority margin of 20\% and an exact noninferiority test with significance level of $\leq 0.05$. Allowing for attrition, enrollment was capped at 120 patients. The $20 \%$ noninferiority margin was chosen to support a practical study size while still able to identify major differences in performance if this were the 
case. Although this margin may seem high, if FCSEMS were worse than UCSEMS by more than approximately $7 \%$ in this trial with 120 patients, the hypothesis would fail to be proven. Analyses were performed on all randomized patients according to the intention-to-treat (ITT) and per protocol (PP) principles.(30) The ITT group included all randomized patients. The PP group included all patients who were treated per protocol and had no major protocol deviations per International Council for Harmonisation of Technical Requirements for Pharmaceuticals for Human Use guidelines. Patients eligible for primary endpoint analysis within the ITT analysis excluded those who died, withdrew consent, or were lost to follow-up before CIS or 1 year as applicable.

Continuous baseline characteristics are presented as median with interquartile range (IQR) and compared between groups using the Wilcoxon rank-sum test. Categorical characteristics are presented as counts and percentages and compared between groups using the Fisher exact test, with corresponding Clopper-Pearson 95\% CIs, where applicable. Kaplan-Meier estimates of endpoint events were calculated for each treatment group and tested using the log-rank test with Greenwood's 95\% CIs, where applicable.

Univariate and multivariate analyses were performed to assess the effect on the primary endpoint of randomization group, age, gender, baseline bilirubin, alkaline phosphate, weight, and Karnofsky score,(31) stent length $4 \mathrm{~cm}$, tumor location, tumor size, tumor stage, and whether chemotherapy included Gemcitabine using Cox proportional hazards regression. Stepwise selection was performed to build the multivariate model, with entry and exit set at $\mathrm{P}>0.1$, and randomized group was forced to stay in model regardless of P value. SAS version 9.4 and StatXact version 11 were used for all analyses. $\mathrm{P}<0.05$ was considered significant for all analyses.

Results

\section{Study Population}

Patients were enrolled between March 2015 and April 2017 at 9 institutions in Belgium (1), Canada (1), Italy (1), Japan (1), Korea (1), United States (4). Of 136 screened patients, 17 were not eligible for randomization, and 119 were randomized (59 to FCSEMS, 60 to UCSEMS) comprising the ITT cohort. Of these, 113 patients were eligible for primary endpoint analysis. 
Two patients, one in each arm, received the stent type not attributed by randomization; thus 111 patients comprised the PP cohort. Six patients were not evaluable for primary endpoint analysis. One patient withdrew consent immediately after uneventful placement of a FCSEMS. Two patients died before potential CIS, one on day 40 of progression of pancreatic cancer after UCSEMS placement, and one on day 44 from iatrogenic causes related to chemotherapy without stent-related adverse events with confirmed FCSEMS patency on CT and ERCP. Three patients were lost to follow-up after placement of a FCSEMS on day 14 day 38, and day 283 without stent-related adverse events and with improved LFTs at last visits.

Of the 113 patients eligible for primary endpoint analysis, $51(45.1 \%)$ patients underwent CIS and $62(54.9 \%)$ patients did not (Figure 1).

Median follow-up for ITT primary endpoint analysis was 206 days (IQR 126-327) overall, 207 days (IQR 136-336) in the FCSEMS group, and 197 days (IQR 121-320) in the UCSEMS group $(\mathrm{P}=0.58)$.

There were no significant differences in baseline characteristics between groups (Table 1) except for the Karnofsky score. Six patients had a low Karnofsky score of 50 or 60, 5 in the UCSEMS and one in the FCSEMS group. Tissue diagnosis was made by EUS fine-needle aspiration or biopsy (EUS-FNA/FNB) in the majority $(111 / 119,93.3 \%)$ and ductal biopsy and/or brushing in a few patients $(8 / 119,6.7 \%)$. All patients had pancreatic adenocarcinoma, more than $30 \%$ stage IIA and approximately $25 \%$ stage IIB.

\section{Stents and Technical Success}

Technical success of stent placement was $99.2 \%$, resulting in 120 SEMS placed in 119 patients. One patient failed technical success of FCSEMS placement, positioned too far into the bile duct, but with its proximal end still below the hilum. Intraprocedural repositioning was not possible and a second FCSEMS was place inside the first one in a transpapillary position. The patient did not undergo CIS and was followed to 1 year without SEMS-related adverse events or reinterventions.

There was no difference in size of stents used between groups $(\mathrm{P}=0.52)$. The great majority (115 (96.6\%)) were $10 \mathrm{~mm}$ in diameter. SEMS length was $6 \mathrm{~cm}$ in $85(71.4 \%)$ and $4 \mathrm{~cm}$ in $32(26.9 \%)$ (Table 1). A $4 \mathrm{~cm}$ stent length was selected in 14 of 32 (43.8\%) FCSEMS and 18 of 32 (56.2\%) 
UCSEMS ( $\mathrm{P}=0.50)$; thus, randomization did not significantly impact the decision to select a 4$\mathrm{cm}$ stent. However, 30 of $32(93.8 \%)$ 4-cm-length stents were selected in significantly more patients with gallbladder in situ compared with 2 of $32(6.2 \%)$ for patients with a prior cholecystectomy $(\mathrm{P}<0.01)$.

\section{Sustained biliary drainage - Primary Endpoint}

Sustained biliary drainage assessed in 113 patients in the primary endpoint ITT cohort was reached in $72.2 \%$ (39/54) of patients with FCSEMS versus $72.9 \%$ (43/59) of patients with UCSEMS ( $\mathrm{P}=0.01)$ as tested to the noninferiority margin of $20 \%$ (Table 2), also demonstrated by the $95 \%$ upper 1 -sided CI limit of $14.8 \%$. The $95 \%$ CI of difference also did not include the $20 \%$ margin and was $0.7 \%(-16.0 \%$ to $17.5 \%)$.

A tipping point sensitivity analysis was conducted to assess the effect of missing data in the FCSEMS test arm by counting them as endpoint failures and eliminating the patient who withdrew consent on Day 0. In this analysis, successful decompression would have been $67.2 \%$ $(39 / 58)$ in the FCSEMS versus $72.9 \%(43 / 59)$ in the UCSEMS group $(\mathrm{P}=0.05)$ as tested to the pre-study noninferiority margin of $20 \%$, thus still proving noninferiority.

In the PP cohort sustained biliary drainage was attained in 71.7\% (38/53) in the FCSEMS and in $72.4 \%(42 / 58)$ in the UCSEMS group ( $\mathrm{P}=0.01)$ as tested to the $20 \%$ noninferiority margin.

Likewise, FCSEMS was noninferior to UCSEMS in the analysis of 51 patients eligible for the primary endpoint who underwent CIS $(83.3 \%$ vs. $81.5 \%$, noninferiority $\mathrm{P}=0.03)$. For the 62 patients who did not undergo CIS and were followed for 1 year, there was a nonsignificant difference $(63.3 \%$ vs $65.6 \%$, noninferiority $\mathrm{P}=0.09)$.

The Kaplan-Meier analysis of ITT patients, in which all 119 patients contribute until the time of failure, death, loss to follow-up, or withdrawal of consent, demonstrated that sustained biliary drainage at 6 months after randomization had a probability of $77.5 \%$ (95\% CI, 65.3\%-89.7\%) for the FCSEMS group and $80.5 \%$ (95\% CI, 69.3\%-91.8\%) in the UCSEMS group, and at 1 year had a probability of $61.0 \%$ (95\% CI, 43.4\%-78.7\%) in the FCSEMS group versus $51.4 \%$ (95\% CI, 28.2\%-74.6\%) in the UCSEMS group ( $\mathrm{P}=0.97)$. In the subgroup of patients that underwent CIS, a Kaplan-Meier analysis of biliary decompression showed success at 6 months in $83.3 \%$ (95\% CI, 68.4\%-98.2\%) in the FCSEMS group and in 84.1\% (95\% CI, 69.8\%-98.4\%) in the UCSEMS group. In the subgroup of patients that did not undergo CIS, the same analysis showed 
success in $74.9 \%$ (95\% CI, 58.7\%-91.2\%) in the FCSEMS group and in 78.9\% (95\% CI, $63.7 \%$ 94.2\%) in the UCSEMS group. The Kaplan-Meier analyses are shown in Figure 2 for the overall ITT cohort, and in Supplementary Figures 1 and 2 respectively for the subset of patients who underwent and did not undergo CIS.

Mean bilirubin levels in the FCSEMS and UCSEMS groups responded from elevated levels before stent placement to rapid normalization maintained after stent placement until the end of follow-up, with a similar time response in both groups, as shown in Supplementary Figure 3.

\section{Neoadjuvant Therapy and Curative Intent Surgery}

No significant differences were observed between the FCSEMS and UCSEMS groups as it pertains to NATx and CIS (Table 2).

Thirteen patients transitioned to palliative management (7) and died while on study or received CIS (6) between day 8 and day 63 after SEMS placement before the planned NATx was initiated.

The rate of patients who completed NATx with delays with recurrent biliary obstruction requiring reintervention was similar in the FCSEMS and UCSEMS groups $(\mathrm{P}=0.99)$.

The rate of patients undergoing CIS was 51 of 113 (45.1\%) overall, and insignificantly different between groups $(\mathrm{P}=0.85)$. The median time to CIS was 110 days, also insignificantly different between groups.

The empiric impression of the surgeon that the presence of a SEMS may have impacted the surgical procedure was similar in the FCSEMS and UCSEMS group $(\mathrm{P}=0.99)$ and did not appear to be related to stent length.

\section{Adverse events and reinterventions}

Overall procedure or SEMS-related SAEs occurred in 23.7\% (14/59) in the FCSEMS versus $20.0 \%(12 / 60)$ in the UCSEMS group ( $\mathrm{P}=0.66)$ (Table 2). Of these 26 related SAEs, 24 resulted in a reintervention. In addition, 7 non-serious AEs resulted in a reintervention. Thus in total there were 31 reinterventions that are listed, including the cause for the reintervention and the type of reintervention in Supplementary Table 1.

For 23 cases of cholangitis and/or biliary obstructive symptoms, the reported causes were 10 UCSEMS ingrowth, 3 FCSEMS and 2 UCSEMS occlusion by sludge or necrotic debris, 4 
FCSEMS migration, 1 FCSEMS and 1 UCSEMS overgrowth, 1 UCSEMS kinking, and 1 FCSEMS had no observed SEMS occlusion or migration. For 6 cases of acute cholecystitis, the presumed cause was cystic duct confluence occlusion by the UCSEMS (2) or FCSEMS (4).

Reinterventions for 10 UCSEMS ingrowth cases were SEMS-in-SEMS placement (8), percutaneous transhepatic biliary drainage (1), or biliary radiofrequency ablation (1). For the 6 cases of acute cholecystitis, the associated reintervention was placement of a percutaneous cholecystostomy tube (4), exchange of the FCSEMS by an UCSEMS (1) or cholecystectomy (1). All 5 cases of FCSEMS migration underwent FCSEMS exchange for another stent. Among the 5 cases of SEMS occlusion by sludge or necrotic debris, FCSEMS were removed and exchanged for another stent (4) or sludge was simply removed from an UCSEMS (1). The case of a gastrointestinal bleed was reported as most likely caused by partial migration over two-thirds of the length of the FCSEMS into the duodenum. The blood clot was left in place and the FCSEMS was removed and exchanged for an UCSEMS 1 month later.

Comparing the FCSEMS and UCSEMS groups, there were significant differences in reasons for SEMS failure between groups (Figure 3), notably tumor ingrowth at $0 \%$ and $16.7 \%(\mathrm{P}<0.01)$, and stent migration in $6.8 \%$ and $0 \%(\mathrm{P}=0.03)$, respectively. Incidence of acute cholecystitis was insignificantly different between FCSEMS and UCSEMS groups, namely respectively $9.3 \%$ (95\% CI, $2.6 \%-22.1 \%$ ) and $4.8 \%$ (95\% CI, 2.6\% - 14.7\%) with a difference of $4.5 \%$ (95\% CI, $8.1 \%-18.2 \% ; \mathrm{P}=0.68)$. One case of acute cholecystitis occurred on day 53 after FCSEMS placement and was associated with proximal FCSEMS migration.

A Kaplan-Meier analysis of survival to 1 year shows no difference between FCSEMS group $60.2 \%$ versus $56.8 \%$ in the UCSEMS group ( $\mathrm{P}=0.57$; Figure 4).

\section{Predictors of Sustained Biliary Drainage}

Significant predictors of failure to attain sustained biliary drainage included use of a stent with a length of $4 \mathrm{~cm}$ (as opposed to 6 or $8 \mathrm{~cm}$ ) and if the gallbladder was in situ. Univariate analysis showed a hazard ratio [HR] $2.9(95 \% \mathrm{CI}, 1.4-6.0 ; \mathrm{P}<0.01)$ if the patient had a $4 \mathrm{~cm}$ stent and a HR of 8.6 (95\% CI, 1.6-45.7; P=0.01) if the gallbladder was present. In a multivariate analysis, 4 cm stent length had a HR of 2.1 (95\% CI, 1.0-4.3; P=0.05) and gallbladder in situ had a HR of 6.9 (95\% CI, 1.3-37.8; P=0.03; Figure 5). 


\section{Discussion}

This prospective multinational trial enrolled patients scheduled for NATx before CIS. All patients had pancreatic adenocarcinoma, confirmed by EUS FNA/FNB, ductal biopsy or brushing before enrollment in this study. All but 6 patients had a Karnofsky score of 70 or better. Patients were randomized to biliary decompression using a FCSEMS or an UCSEMS. FCSEMSs were shown to be noninferior to UCSEMSs for sustained biliary drainage on an ITT basis until CIS or to 1 year $(72.2 \%$ vs. $72.9 \%$, noninferiority $\mathrm{P}=0.01)$. A Kaplan-Meier analysis at 1 year after randomization confirms insignificant differences in sustained biliary drainage and shows similar times to reintervention when using FCSEMSs or UCSEMSs.

Concerns have been raised about tissue ingrowth requiring reintervention when using UCSEMSs, and of migration and acute cholecystitis when using FCSEMSs(32), either of which can guide stent type choice by the endoscopist. Of 31 patients experiencing SEMS failure requiring reintervention before CIS or before 1 year in patients who do not undergo CIS there were significant differences in reasons for SEMS failure between groups. Tumor ingrowth requiring intervention was significantly more likely in the UCSEMS than in the FCSEMS group $(\mathrm{P}<0.01)$. For stent migration the opposite was true $(\mathrm{P}=0.03)$. Acute cholecystitis had a nonsignificant tendency to occur more frequently when using FCSEMSs $(\mathrm{P}=0.68)$.

Improper stent functionality causing delays or noncompletion of chemotherapy were not different for FCSEMS and UCSEMS. There was also no difference between the FCSEMS versus UCSEMS groups in time to CIS (114 vs 106.5 days, $\mathrm{P}=0.94$ ). This establishes that the UCSEMS and FCSEMS choices are insignificantly different in providing proper biliary drainage during NATx.

In our study, the only significant predictors of failure to decompress biliary obstruction were SEMS of $4 \mathrm{~cm}$ length compared to $6 \mathrm{~cm}$ and $8 \mathrm{~cm}$ length and the presence of a gallbladder. Increased risk of failure occurred with a multivariate HR of 2.1 for SEMS of $4 \mathrm{~cm}$ length compared to $6 \mathrm{~cm}$ and $8 \mathrm{~cm}$ length, and HR of 6.9 for patients with gallbladder in situ. It is noteworthy that selection of the $4 \mathrm{~cm}$ stent length was significantly more common among patients with gallbladder in situ compared to patients with a prior cholecystectomy $(\mathrm{P}<0.01)$. 
In a recent retrospective cohort study with 645 patients, covered SEMSs (CSEMSs) and UCSEMSs had similar rates of clinical success in relief of bile duct obstruction and patency duration; however, among those with gallbladder in situ, CSEMS use was associated with increased acute cholecystitis; and in multivariable analysis, CSEMS use was associated with increased migration.(32) A retrospective series from Korea published in 2006 (33) concluded that acute cholecystitis occurred in 15 of 155 (9.7\%) patients receiving SEMS for management of malignant biliary obstruction and was more likely when the tumor involved the cystic duct confluence. Also in 2006 (34) a Japanese retrospective series in 246 patients with unresectable distal malignant bile duct strictures receiving 171 CSEMSs and 75 UCSEMSs, 13 (5.3\%) of patients developed acute cholecystitis, confirming association with tumor involvement at the cystic duct orifice, but not associated with CSEMS or UCSEMS type. More recently, in 2014, the same group in Japan (35) analyzed risk factors for CSEMS migration in a retrospective series of 290 patients and concluded that CSEMS migration occurred in $15.2 \%$, associated with low radial force of the CSEMS, administration of chemotherapy, and duodenal tumoral involvement. Given comparable success rates of preoperative biliary decompression before and during NATx in pancreatic cancer patients and given that the price of the FCSEMS is higher than that of UCSEMSs in several markets, the removable aspect of the FCSEMS should be emphasized in settings of uncertain diagnosis and uncertain patient management plan. When cancer is not proven, FCSEMS placement can prevent, for example in autoimmune pancreatitis, the potential disaster of having placed an UCSEMS in a benign biliary stricture. If a FCSEMS was placed in the case of indeterminate biliary strictures and malignancy is subsequently confirmed, exchange of the FCSEMS for an UCSEMS is not warranted given findings of our study.

There are several limitations to this study. Firstly, the study was fairly small, thus conclusions could be drawn from the primary endpoint, but analyses pertaining to different site-by-site medical oncology treatment regimens were not possible. Secondly, 2 patients, 1 per group, were not treated as randomized. Fortunately, a sensitivity analysis of this discrepancy between the ITT and PP analyses confirmed that this had no effect on the primary endpoint analysis. Last, this study was sponsored by the manufacturer of the UCSEMS and FCSEMS used in the study. An effort was made to mitigate unwanted bias by assuring data sharing and strong collaboration and oversight by the investigators throughout the study, from protocol development through data analyses and manuscript writing and review. Key representatives of the manufacturer 
participated in these processes and hence are featured in the author list. Although this study was supported by the manufacturer of the SEMS used in this study, the Wallflex Biliary UCSEMS and FCSEMS are the only ones marketed in the United States and cleared by the FDA for relief of malignant biliary obstruction before surgery.

In conclusion, this international randomized study demonstrated noninferiority of FCSEMS compared to UCSEMS for preoperative management of biliary obstruction in pancreatic cancer patients in the setting of NATx. Mechanisms of stent dysfunction depended on stent type-FCSEMS or UCSEMS-and attaining sustained biliary drainage depended on stent length and presence of gallbladder.

\section{Financial Support and Acknowledgements}

This study was sponsored by Boston Scientific Corporation.

The authors who conducted study procedures acknowledge their sub-investigators Dr. Dongwook $\mathrm{Oh}^{1}$, Dr. Evan Fogel ${ }^{2}$, Dr. Jeff Easler ${ }^{2}$, Dr. Glen Lehman ${ }^{2}$, Dr. James Watkins ${ }^{2}$, Dr. Lee McHenry ${ }^{2}$, Dr Ihab El-Hajj ${ }^{2}$, Dr. Abdul Khan ${ }^{3}$, Dr. Murad Abu Rajab ${ }^{3}$, Dr. Darren Ballard ${ }^{3}$, Dr. Georgios Papachristou ${ }^{4}$, Dr. Mordechai Rabinovitz ${ }^{4}$, Dr. Simon Bouchard ${ }^{5}$, Dr. Marylène Plasse $^{5}$, Dr. Andrea Tringali ${ }^{6}$, Dr. Ivo Boskoski ${ }^{6}$, Dr. Vincent Huberty ${ }^{7}$, Dr. Pierre Eisendrath ${ }^{7}$, Dr. Marianna Arvanitakis ${ }^{7}$, Dr. Vincent Picozzi ${ }^{10}$, Dr. Shayan Irani ${ }^{10}$, Dr. Michael Larsen ${ }^{10}$, and Dr. Andrew Ross ${ }^{10}$. Together they comprise the "Biliary SEMS during neoadjuvant therapy study group". Professor Hiroyuki Isayama and Professor Dong Wan Seo served as lead investigators during the conduct of the trial. They also wish to thank Joanna Suomi for her expert contributions to this manuscript as a medical writer. The authors that are Boston Scientific Corporation employees acknowledge contributions to study conduct and safety review by their colleagues Lina Ginnetti, Nguyet Nguyen, and Dr. Thomas Bowman. 


\section{Tables and Figures}

\section{Figure 1. Patient Flowchart.}

Abbreviations: CIS, curative intent surgery; FCSEMS, fully-covered, self-expanding metal stents; ITT, intention-to-treat; UCSEMS, uncovered, self-expanding metal stents. Enrollment cap was N=120 patients, but one patient was removed from the ITT cohort because of treatment with a SEMS before randomization. *Deaths due to disease progression/neoadjuvant therapy.

Figure 2. Kaplan-Meier analysis of primary endpoint in the intention-to-treat analysis set. Kaplan-Meier curves are shown for the primary endpoint, namely sustained biliary drainage, according to randomized treatment arm in an ITT analysis with intended follow-up to CIS where applicable, or to 1 year otherwise. Sustained biliary drainage occurred in $61.0 \%$ of patients with FCSEMS versus $51.4 \%$ of patients with UCSEMS at 1 year $(\mathrm{P}=0.84)$ in an analysis of all $\mathrm{N}=119$ patients. Abbreviations: CI, confidence interval; DBO, sustained biliary drainage; FC, fully-covered; UC, uncovered.

Figure 3. Principal reasons for reintervention during the index procedure by randomized treatment group. Abbreviations: FCSEMS, fully covered self-expanding metal stents; UCSEMS, uncovered self-expanding metal stents.

\section{Figure 4. Kaplan-Meier Analysis of Survival to 1 Year.}

Kaplan-Meier curves are shown for survival to 1 year according to randomized treatment arm. $60.2 \%$ of patients in FCSEMS group versus $56.8 \%$ of patients with UCSEMS at 1 year $(\mathrm{P}=0.57)$. Abbreviations: CI, confidence interval; FC, fully covered; UC, uncovered.

Figure 5. Predictors of failure to attain sustained biliary drainage. Univariate and multivariate analysis of failure to attain sustained biliary drainage. Abbreviations: SEMS, self-expanding metal stent. 
Table 1. Baseline characteristics.

Baseline characteristics are presented for the intention-to-treat cohort.

\begin{tabular}{|c|c|c|c|}
\hline Patient characteristics* & $\begin{array}{c}\text { FCSEMSs } \\
\mathrm{N}=59\end{array}$ & $\begin{array}{c}\text { UCSEMSs } \\
\qquad \begin{array}{c}\mathrm{N}=60 \\
\end{array}\end{array}$ & $P$ value \\
\hline Age & 67.0 (IQR 58.0-71.0) & 65.0 (IQR 58.5-73.0) & 0.89 \\
\hline Male & $55.9 \%(33 / 59)$ & $55.0 \%(33 / 60)$ & 0.99 \\
\hline Weight $(\mathrm{kg})$ & 77.7 (IQR 62.3-87) & 78.4 (IQR 65.1-90.4) & 0.47 \\
\hline Gallbladder in Situ & $72.9 \%(43 / 59)$ & $70 \% \%(42 / 60)$ & 0.84 \\
\hline Karnofsky Score & 90.0 (IQR 80.0-100.0) & 80.0 (IQR 80.0-90.0) & 0.03 \\
\hline & & & \\
\hline Tumor characteristics & & & \\
\hline Tumor Size, $\mathrm{cm}$ & $3.1 \pm 1.4(59)$ & $2.9 \pm 50.9(60)$ & 0.93 \\
\hline Tumor Stage & $\bar{y}$ & & 0.82 \\
\hline IA - T1 NO MO & $11.9 \%(7 / 59)$ & $5.0 \%(3 / 60)$ & \\
\hline $\mathrm{IB}-\mathrm{T} 2 \mathrm{NO} \mathrm{MO}$ & $8.5 \%(5 / 59)$ & $10.0 \%(6 / 60)$ & \\
\hline IIA - T3 NO MO & $32.2 \%(19 / 59)$ & $40.0 \%(24 / 60)$ & \\
\hline IIB - T1 N1 MO T2 N1 MO T3 N1 MO & $25.4 \%(15 / 59)$ & $25.0 \%(15 / 60)$ & \\
\hline III - T4 Any N M0 & $8.5 \%(5 / 59)$ & $8.3 \%(5 / 60)$ & \\
\hline Unknown & $13.6 \%(8 / 59)$ & $11.7 \%(7 / 60)$ & \\
\hline \multicolumn{4}{|l|}{ Procedure characteristics } \\
\hline Technical Success & $98.3 \%(58 / 59)$ & $100 \%(60 / 60)$ & 0.50 \\
\hline Biliary sphincterotomy & $91.5 \%(54 / 59)$ & $93.3 \%(56 / 60)$ & 0.74 \\
\hline
\end{tabular}




\begin{tabular}{l|c|c|c}
\hline Prophylactic antibiotics & $47.5 \%(28 / 59)$ & $46.7 \%(28 / 60)$ & 0.99 \\
\hline Stent Sizes & & & 0.52 \\
\hline $8 \mathrm{~mm} \times 4 \mathrm{~cm}$ & $0 \%(0 / 59)$ & $3.3 \%(2 / 60)$ & \\
\hline $8 \mathrm{~mm} \times 6 \mathrm{~cm}$ & $1.7 \%(1 / 59)$ & $0 \%(0 / 60)$ & \\
\hline $8 \mathrm{~mm} \times 8 \mathrm{~cm}$ & $1.7 \%(1 / 59)$ & $0 \%(0 / 60)$ & \\
\hline $10 \mathrm{~mm} \times 4 \mathrm{~cm}$ & $23.7 \%(14 / 59)$ & $26.7 \%(16 / 60)$ & \\
\hline $10 \mathrm{~mm} \times 6 \mathrm{~cm}$ & $72.9 \%(43 / 59)$ & $68.3 \%(41 / 60)$ & \\
\hline $10 \mathrm{~mm} \times 8 \mathrm{~cm}$ & $0 \%(0 / 59)$ & $1.7 \%(1 / 60)$ & \\
\hline
\end{tabular}

Characteristics are presented as \% (n) and medians with interquartile ranges (IQR).

Abbreviations: IQR, interquartile range; FC-SEMSs, fully-covered self-expanding metal stents; UC-SEMSs, uncovered self-expanding metal stents. 
Table 2. Key Outcomes.

\begin{tabular}{|c|c|c|c|}
\hline Effectiveness Outcome & FCSEMSs & UCSEMSs & $P$ value \\
\hline Sustained biliary drainage (Primary Endpoint) & $72.2 \%(39 / 54)$ & $72.9 \%(43 / 59)$ & $0.01 *$ \\
\hline Neoadjuvant Therapy Not Completed ${ }^{* *}$ & $18.2 \%(10 / 55)$ & $28.8 \%(15 / 52)$ & 0.25 \\
\hline Neoadjuvant Therapy Completed with Delay & $16.4 \%(9 / 55)$ & $11.5 \%(6 / 52)$ & 0.58 \\
\hline $\begin{array}{l}\text { With recurrent biliary obstruction requiring } \\
\text { reintervention }\end{array}$ & $3.6 \%(2 / 55)$ & $1.9 \%(1 / 52)$ & 0.99 \\
\hline Patients with CIS & $43.6 \%(24 / 55)$ & $45.8 \%(27 / 59)$ & 0.58 \\
\hline SEMS Impacted surgical procedure & $13.0 \%(3 / 24)$ & $15.4 \%(4 / 27)$ & 0.99 \\
\hline Median Time to CIS (N=50) & $\begin{array}{c}114.0 \\
\text { (IQR 90.5-168.5) }\end{array}$ & $\begin{array}{c}106.5 \\
(\text { IQR } 83.0-211.0)\end{array}$ & 0.94 \\
\hline Procedure-Related/Stent-Related Serious AEs & FCSEMS & UCSEMS & P Value \\
\hline Acute cholecystitis & $9.3 \%(4 / 43)$ & $4.8 \%(2 / 42)$ & 0.68 \\
\hline Acute pancreatitis $* * *$ & $1.7 \%(1 / 59)$ & $0 \%(0 / 60)$ & 0.50 \\
\hline Cholangitis & $15.3 \%(9 / 59)$ & $13.3 \%(8 / 60)$ & 0.80 \\
\hline Gastrointestinal hemorrhage & $1.7 \%(1 / 59)$ & $0 \%(0 / 60)$ & 0.50 \\
\hline Abdominal pain & $1.7 \%(1 / 59)$ & $3.3 \%(2 / 60)$ & 0.99 \\
\hline CBD Obstruction or Abnormal LFTs & $3.4 \%(2 / 59)$ & $1.7 \%(1 / 60)$ & 0.62 \\
\hline Liver abscess & $0 \%(0 / 59)$ & $1.7 \%(1 / 60)$ & 0.99 \\
\hline Total & $23.7 \%(14 / 59)$ & $20.0 \%(12 / 60)$ & 0.66 \\
\hline
\end{tabular}

Abbreviations: FC-SEMSs, fully-covered self-expanding metal stents; UC-SEMSs, uncovered self-expanding metal stents.

*Noninferiority $P$ value.

**None with recurrent biliary obstruction requiring reintervention

***Excludes reports of mild acute pancreatitis. 


\section{References}

1. Jemal A, Siegel R, Xu J, Ward E. Cancer statistics, 2010. CA Cancer J Clin 2010;60:277300.

2. Hidalgo M. Pancreatic cancer. N Engl J Med 2010;362:1605-17.

3. Lowy AM. Neoadjuvant therapy for pancreatic cancer. J Gastrointest Surg. 2008;12:1600-8.

4. Evans DB, Wolff RA, Crane CH. Neoadjuvant strategies for pancreatic cancer. Oncology (Williston Park). 2001;15:727-37; discussion 41-4, 47.

5. Greer SE, Pipas JM, Sutton JE, Zaki BI, Tsapakos M, Colacchio TA, et al. Effect of neoadjuvant therapy on local recurrence after resection of pancreatic adenocarcinoma. J Am Coll Surg. 2008;206:451-7.

6. Tempero MA, Malafa MP, Al-Hawary M, Asbun H, Bain A, Behrman SW, et al. Pancreatic Adenocarcinoma, Version 2.2017, NCCN Clinical Practice Guidelines in Oncology. J Natl Compr Canc Netw. 2017;15:1028-61.

7. Wolff RA. Neoadjuvant therapy for resectable and borderline resectable adenocarcinoma of the pancreas. Curr Drug Targets. 2012;13:781-8.

8. Garcea G, Chee W, Ong SL, Maddern GJ. Preoperative biliary drainage for distal obstruction: the case against revisited. Pancreas. 2010;39:119-26.

9. Coates JM, Beal SH, Russo JE, Vanderveen KA, Chen SL, Bold RJ, et al. Negligible effect of selective preoperative biliary drainage on perioperative resuscitation, morbidity, and mortality in patients undergoing pancreaticoduodenectomy. Arch Surg. 2009;144:841-7.

10. Kimmings AN, van Deventer SJ, Obertop H, Rauws EA, Huibregtse K, Gouma DJ. Endotoxin, cytokines, and endotoxin binding proteins in obstructive jaundice and after preoperative biliary drainage. Gut. 2000;46:725-31.

11. van der Gaag NA, de Castro SM, Rauws EA, Bruno MJ, van Eijck CH, Kuipers EJ, et al. Preoperative biliary drainage for periampullary tumors causing obstructive jaundice; DRainage vs. (direct) OPeration (DROP-trial). BMC Surg. 2007;7:3.

12. Crippa S, Cirocchi R, Partelli S, Petrone MC, Muffatti F, Renzi C, et al. Systematic review and meta-analysis of metal versus plastic stents for preoperative biliary drainage in resectable periampullary or pancreatic head tumors. Eur J Surg Oncol. 2016;42:1278-85. 
13. Wasan SM, Ross WA, Staerkel GA, Lee JH. Use of expandable metallic biliary stents in resectable pancreatic cancer. Am J Gastroenterol. 2005;100:2056-61.

14. Sawas T, Al Halabi S, Parsi MA, Vargo JJ. Self-expandable metal stents versus plastic stents for malignant biliary obstruction: a meta-analysis. Gastrointest Endosc. 2015;82:25667.e7.

15. Decker C, Christein JD, Phadnis MA, Wilcox CM, Varadarajulu S. Biliary metal stents are superior to plastic stents for preoperative biliary decompression in pancreatic cancer. Surg Endosc. 2011;25:2364-7.

16. Almadi MA, Barkun A, Martel M. Plastic vs. Self-Expandable Metal Stents for Palliation in Malignant Biliary Obstruction: A Series of Meta-Analyses. Am J Gastroenterol. 2017;112:260-73.

17. Almadi MA, Barkun AN, Martel M. No benefit of covered vs uncovered self-expandable metal stents in patients with malignant distal biliary obstruction: a meta-analysis. Clin Gastroenterol Hepatol. 2013;11:27-37.e1.

18. Li J, Li T, Sun P, Yu Q, Wang K, Chang W, et al. Covered versus Uncovered SelfExpandable Metal Stents for Managing Malignant Distal Biliary Obstruction: A Meta-Analysis. PLoS One. 2016;11:e0149066.

19. Chen MY, Lin JW, Zhu HP, Zhang B, Jiang GY, Yan PJ, et al. Covered Stents versus Uncovered Stents for Unresectable Malignant Biliary Strictures: A Meta-Analysis. Biomed Res Int. 2016;2016:6408067.

20. Y A, T H, MA K, BW K, S K, MK I, et al. Risk of Post-ERCP Pancreatitis after placement of Covered versus Uncovered Self-Expandable Biliary Metal Stents: A Systematic Review and Meta-Analysis. JOP J Pancreas (Online). 2015;16:452-8.

21. Saleem A, Leggett CL, Murad MH, Baron TH. Meta-analysis of randomized trials comparing the patency of covered and uncovered self-expandable metal stents for palliation of distal malignant bile duct obstruction. Gastrointest Endosc. 2011;74:321-7.e1-3.

22. Moole H, Bechtold ML, Cashman M, Volmar FH, Dhillon S, Forcione D, et al. Covered versus uncovered self-expandable metal stents for malignant biliary strictures: A meta-analysis and systematic review. Indian J Gastroenterol. 2016;35:323-30. 
23. Adams MA, Anderson MA, Myles JD, Khalatbari S, Scheiman JM. Self-expanding metal stents (SEMS) provide superior outcomes compared to plastic stents for pancreatic cancer patients undergoing neoadjuvant therapy. J Gastrointest Oncol. 2012;3:309-13.

24. Singal AK, Ross WA, Guturu P, Varadhachary GR, Javle M, Jaganmohan SR, et al. Selfexpanding metal stents for biliary drainage in patients with resectable pancreatic cancer: singlecenter experience with 79 cases. Dig Dis Sci. 2011;56:3678-84.

25. Aadam AA, Evans DB, Khan A, Oh Y, Dua K. Efficacy and safety of self-expandable metal stents for biliary decompression in patients receiving neoadjuvant therapy for pancreatic cancer: a prospective study. Gastrointest Endosc. 2012;76:67-75.

26. Mullen JT, Lee JH, Gomez HF, Ross WA, Fukami N, Wolff RA, et al.

Pancreaticoduodenectomy after placement of endobiliary metal stents. J Gastrointest Surg. 2005;9:1094-104; discussion 104-5.

27. Kahaleh M, Brock A, Conaway MR, Shami VM, Dumonceau JM, Northup PG, et al. Covered self-expandable metal stents in pancreatic malignancy regardless of resectability: a new concept validated by a decision analysis. Endoscopy. 2007;39:319-24.

28. Pop GH, Richter JA, Sauer B, Rehan ME, Ho HC, Adams RB, et al. Bridge to surgery using partially covered self-expandable metal stents (PCMS) in malignant biliary stricture: an acceptable paradigm? Surg Endosc. 2011;25:613-8.

29. Lawrence C, Howell DA, Conklin DE, Stefan AM, Martin RF. Delayed pancreaticoduodenectomy for cancer patients with prior ERCP-placed, nonforeshortening, selfexpanding metal stents: a positive outcome. Gastrointest Endosc. 2006;63:804-7.

30. Mauri L, D'Agostino RB. Challenges in the Design and Interpretation of Noninferiority Trials. N Engl J Med. 2017;377:1357-67.

31. Karnofsky D, Abelmann W, Craver L, Burchenal J. The Use of the Nitrogen Mustards in the Palliative Treatment of Carcinoma - with Particular Reference to Bronchogenic Carcinoma. Cancer. 1948;1:634-56.

32. Jang S, Stevens T, Parsi M, Lopez R, Zuccaro G, Dumot J, et al. Association of covered metallic stents with cholecystitis and stent migration in malignant biliary stricture. Gastrointest Endosc. 2018;87:1061-70. 
33. Suk KT, Kim HS, Kim JW, Baik SK, Kwon SO, Kim HG, et al. Risk factors for cholecystitis after metal stent placement in malignant biliary obstruction. Gastrointest Endosc. 2006;64:522-9.

34. Isayama H, Kawabe T, Nakai Y, Tsujino T, Sasahira N, Yamamoto N, et al. Cholecystitis after metallic stent placement in patients with malignant distal biliary obstruction. Clin Gastroenterol Hepatol. 2006;4:1148-53.

35. Nakai Y, Isayama H, Kogure H, Hamada T, Togawa O, Ito Y, et al. Risk factors for covered metallic stent migration in patients with distal malignant biliary obstruction due to pancreatic cancer. J Gastroenterol Hepatol. 2014;29:1744-9. 


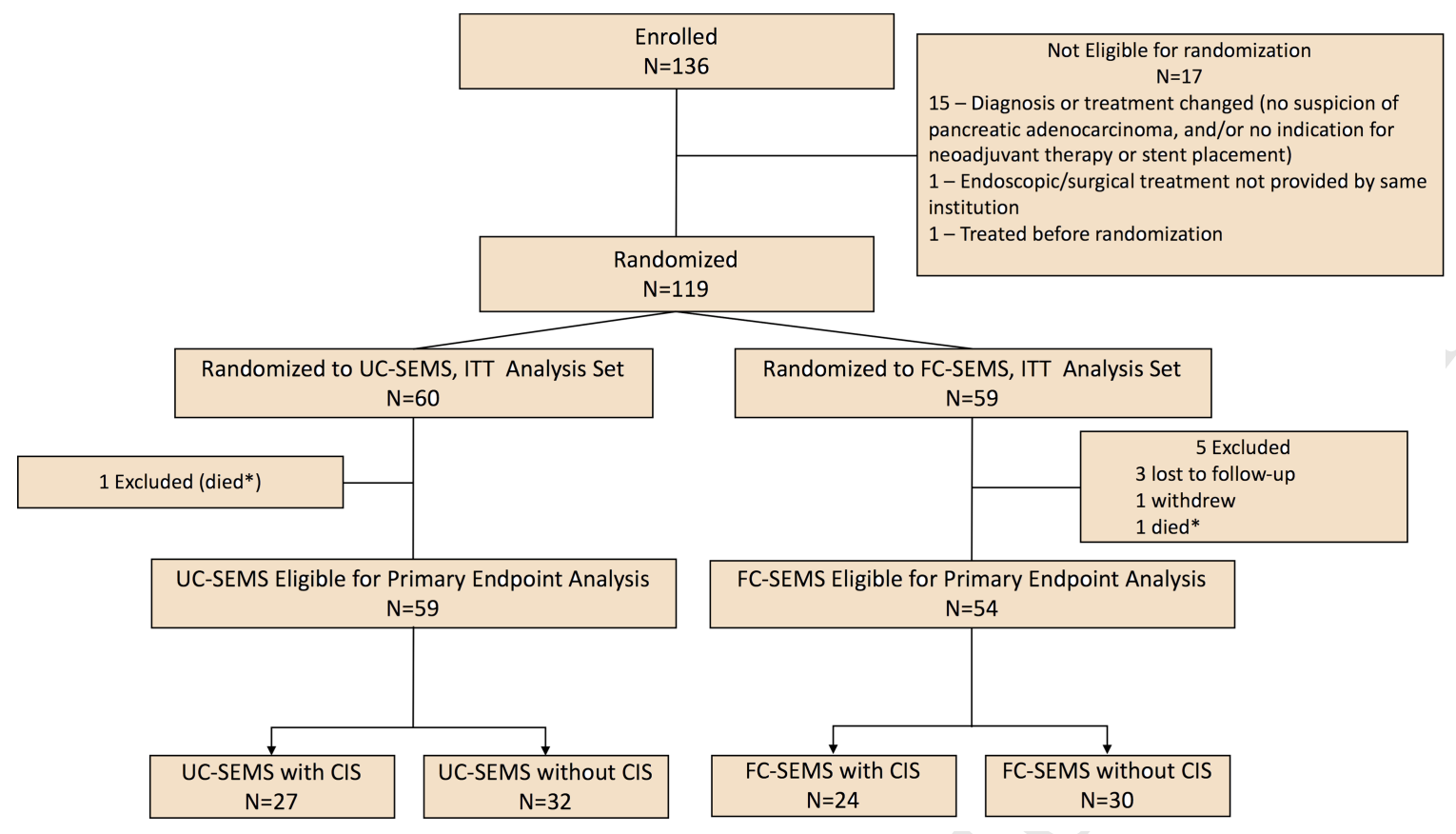




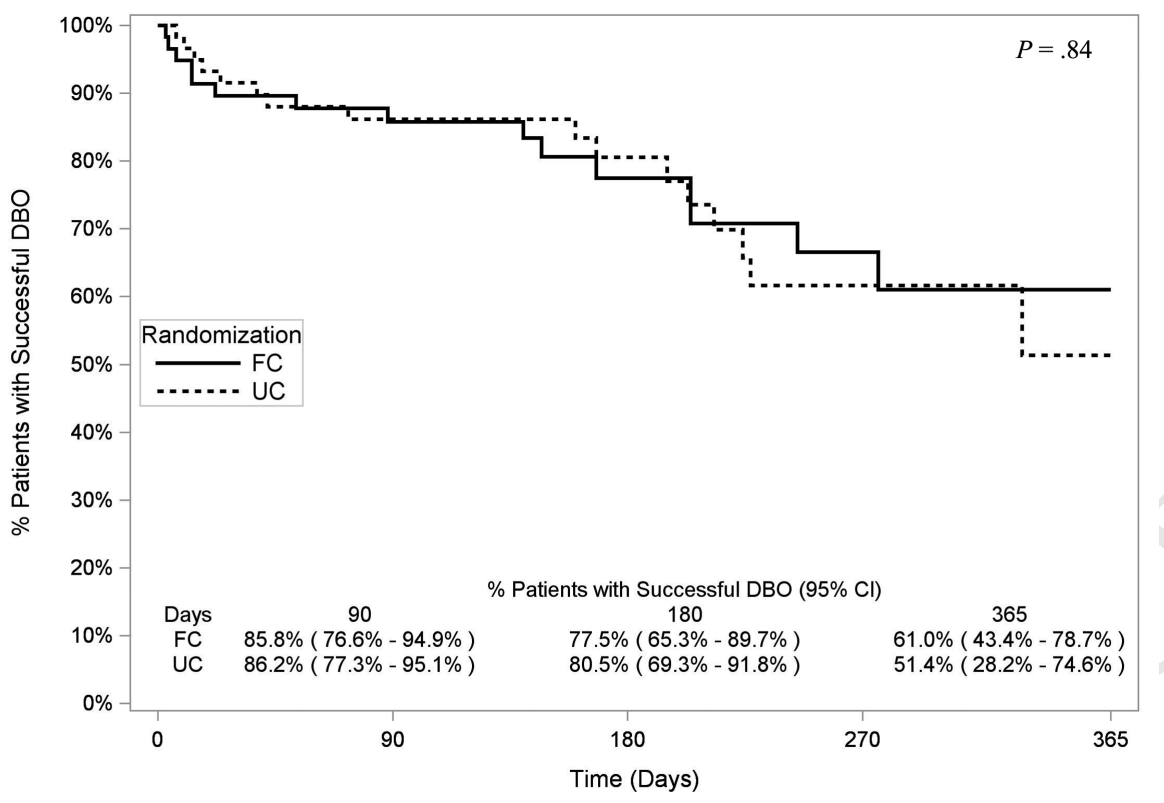

At Risk 


\section{Reason for Reintervention}

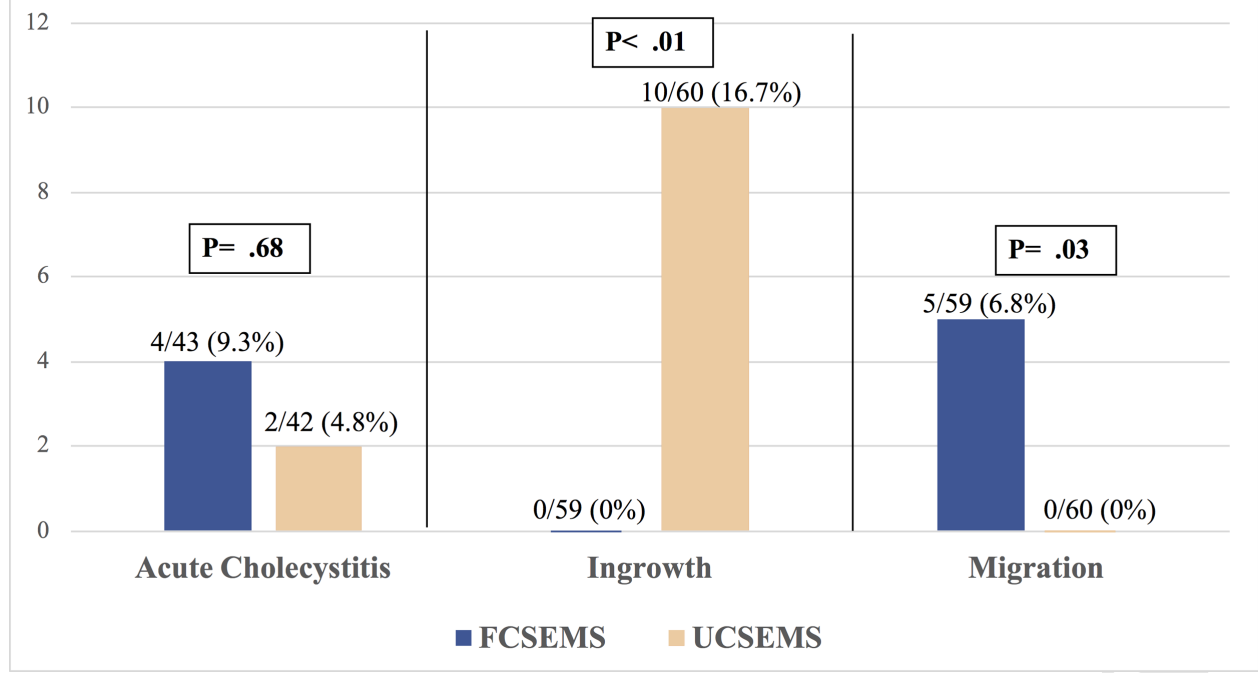




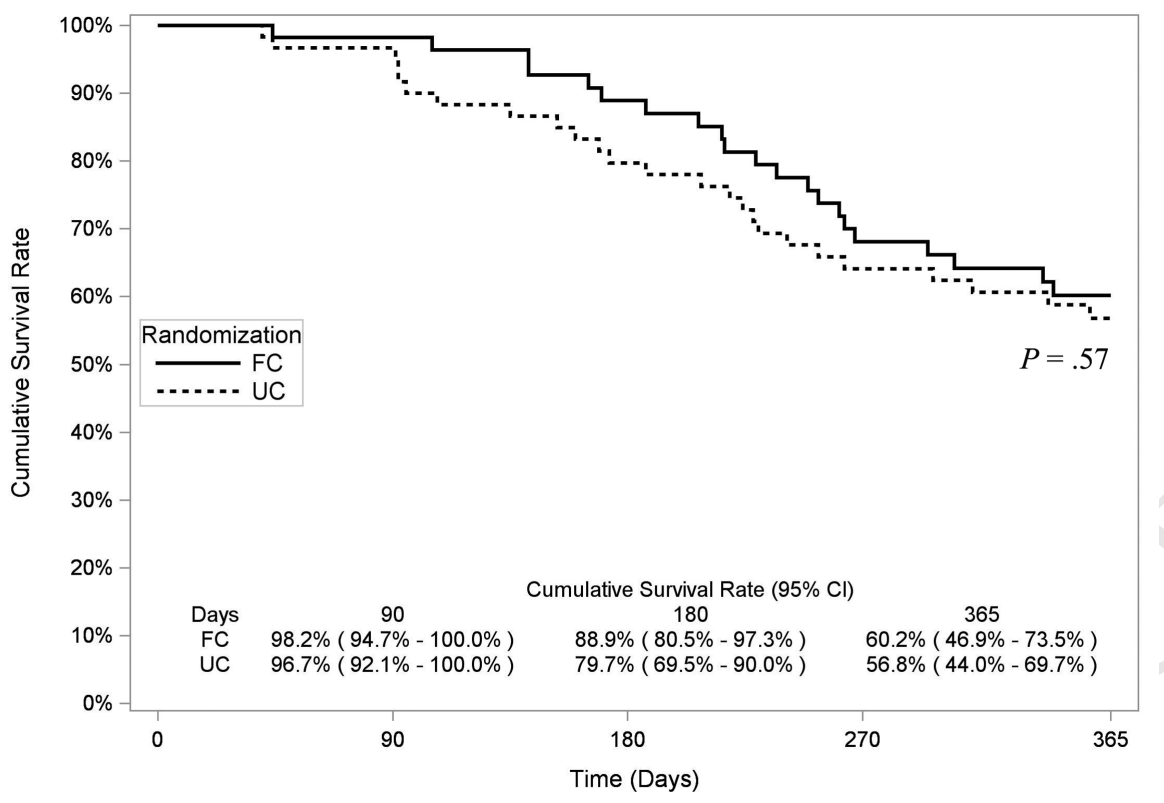

At Risk 


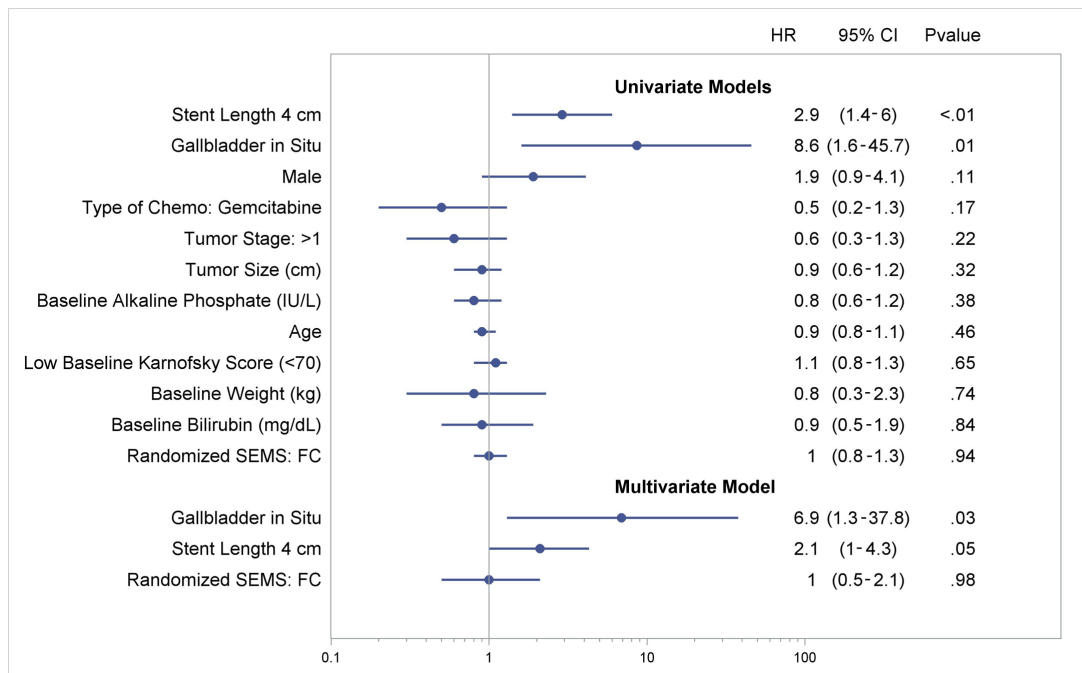




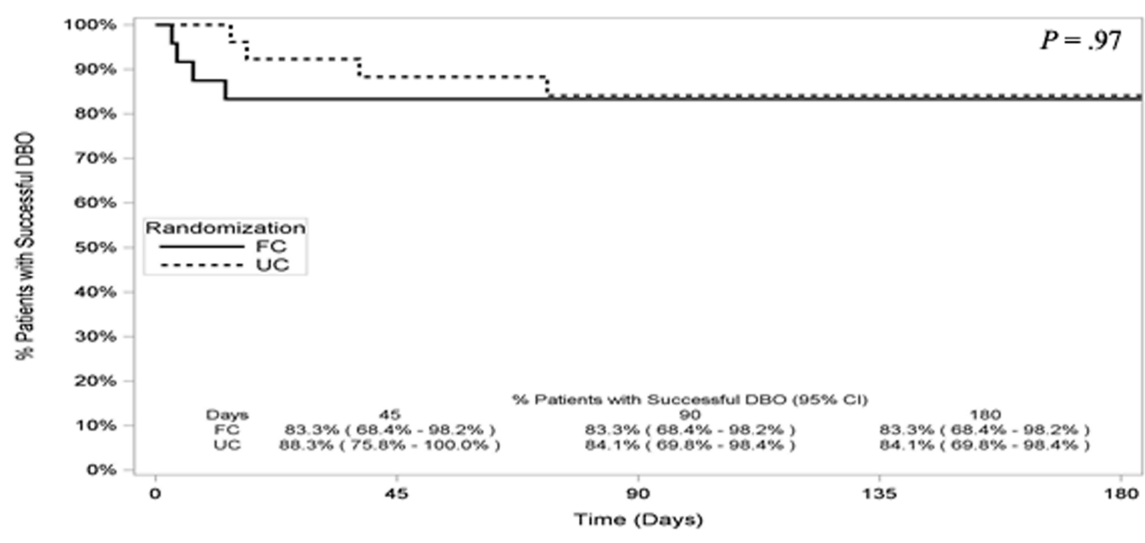

At Risk

$\begin{array}{ll}\text { FC } & 24 \\ \text { UC } & 27\end{array}$

19
22

16
18

11

${ }_{8}^{5}$ 


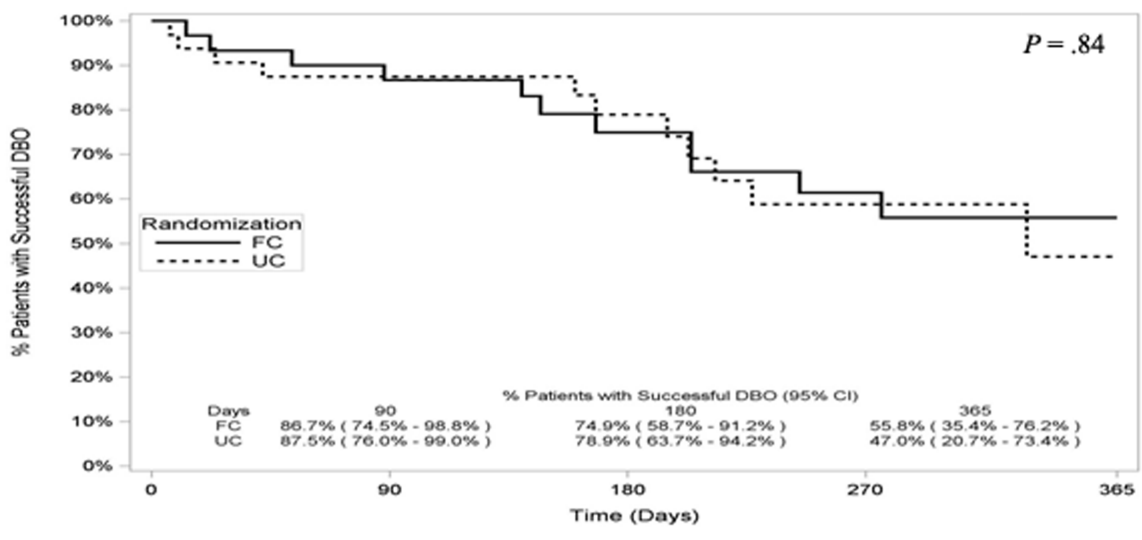

At Risk 


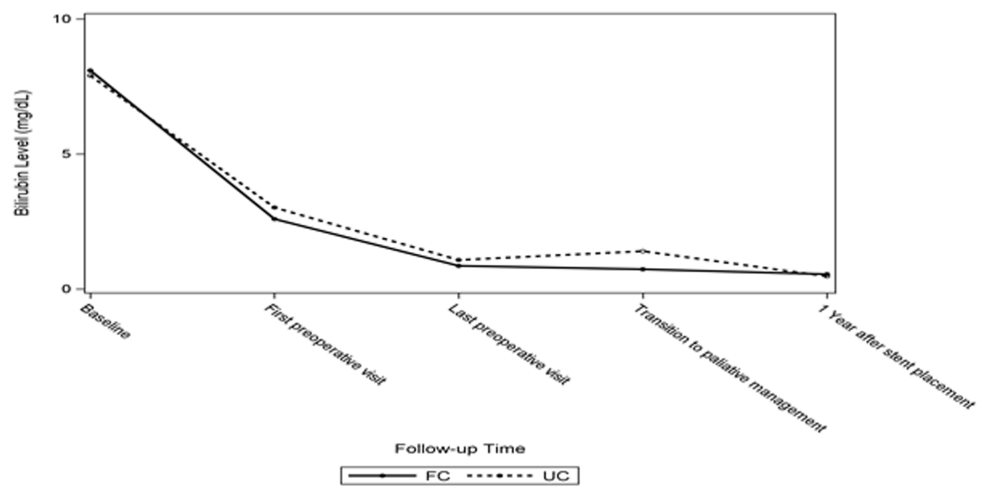




\section{Supplemental Appendix}

Covered and uncovered biliary metal stents provide similar relief of biliary obstruction during neoadjuvant therapy in pancreatic cancer: a randomized trial

Short Title: Biliary metal stents in neoadjuvant therapy

Dong Wan Seo ${ }^{1}$; Stuart Sherman ${ }^{2}$ K Kulwinder S. Dua ${ }^{3}$; Adam Slivka ${ }^{4}$; Andre Roy ${ }^{5}$; Guido Costamagna $^{6}$; Jacques Deviere ${ }^{7}$; Joyce Peetermans ${ }^{8}$; Matthew Rousseau ${ }^{8}$; Yousuke Nakai ${ }^{9}$; Hiroyuki Isayama ${ }^{9 *}$, and Richard Kozarek ${ }^{10}$ for the "Biliary SEMS during neoadjuvant therapy study group" 


\section{Appendix 1.}

Adverse events were predefined as follows, taken directly from van der Gaag N, Rauws E, van Eijck C, Bruno M, van der Harst E, et al. Preoperative biliary drainage for cancer of the head of the pancreas. N Engl J Med 2010;362;129-37.

- Acute pancreatitis: Abdominal pain and a serum concentration of pancreatic enzymes (amylase or lipase) three or more times the upper limit of normal, that required more than one night of hospitalization

- Acute cholecystitis: No suggestive clinical or radiographic signs of acute cholecystitis before the procedure and if emergency cholecystectomy is subsequently required

- Perforation: Retroperitoneal or bowel-wall perforation documented by any radiographic technique or direct visual evidence

- Stent Occlusion: Recurring obstructive jaundice with necessary stent replacement

- Pancreaticojejunostomy leakage: Drain output of any measurable volume of fluid on or after postoperative day 3 with an amylase content greater than 3 times the serum amylase activity, graded according to clinical course (ISGPS grade A, B, C), or direct visual evidence of defect at anastomosis

- Delayed gastric emptying: Gastric stasis requiring nasogastric intubation for 10 days or more, or the inability to tolerate a regular (solid) diet on or before the fourteenth postoperative day, not due to sequelae of intra-abdominal complications (ie, abscess, anastomotic leakage)

- Biliary leakage: Bilirubin in abdominal drain or dehiscence found at laparotomy

- Gastro/-duodenojejunostomy leakage: Conclusive radiographic or direct visual evidence of a defect of the anastomosis

- Intra-abdominal abscess formation: Intra-abdominal fluid collection with positive cultures identified by ultrasonography or computed tomography, associated with persistent fever and elevations of white blood cells

- Wound infection: Requiring intervention otherwise considered as minor adverse event 
- Portal Vein Thrombosis: Conclusive radiologic evidence of thrombosis

- Cholangitis: Elevation in temperature more than $38^{\circ} \mathrm{C}$, thought to have a biliary cause, without concomitant evidence of acute cholecystitis, requiring intervention

- Hemorrhage: Bleeding after the index procedure requiring transfusion of $\geq 4$ units of packed cells within a 24-hour period, or leading to relaparotomy/intervention

- (Emergency) (re)laparotomy: Any (other) reason after either preoperative biliary drainage or another surgical procedure

- Pneumonia: Pulmonary infection with radiological confirmation and requiring antibiotic treatment

- Mortality: In-hospital death, due to protocol adverse events or any cause, including progression of disease, within the study period 


\section{Supplementary Figure 1.}

Kaplan-Meier analysis of primary endpoint in patients who underwent curative intent surgery in the intention-to-treat analysis set.

Kaplan-Meier curves are shown for sustained biliary drainage, according to randomized treatment arm in an ITT analysis for the subset of patients who underwent CIS. Sustained biliary drainage occurred in $83.3 \%$ of patients with FCSEMS versus $84.1 \%$ of patients with UCSEMS at 1 year $(P=.97)$ in an analysis of $\mathrm{N}=51$ patients who underwent CIS.

Abbreviations: CI, confidence interval; FC, fully covered; UC, uncovered.

\section{Supplementary Figure 2.}

Kaplan-Meier analysis of primary endpoint in patients who did not undergo curative intent surgery in the intention-to-treat analysis set.

Kaplan-Meier curves are shown for sustained biliary drainage, according to randomized treatment arm in an ITT analysis for the subset of patients who did not undergo CIS. Sustained biliary drainage occurred in 55.8\% of patients with FCSEMS versus $47.0 \%$ of patients with UCSEMS at 1 year $(P=.84)$ in an analysis of $\mathrm{N}=62$ patients who did not undergo CIS.

Abbreviations: CI, confidence interval; FC, fully covered; UC, uncovered.

\section{Supplementary Figure 3.}

\section{Mean Bilirubin level as a function of follow-up visits}

Graph shows the mean Bilirubin level at 5 follow-up visits. Given that some patients underwent CIS and some did not, the number of patients per for whom the Bilirubin levels are documented varies per protocol at the various study visits. Specifically, the number of patients at each study visit in the graphic below is as follows: Baseline $\mathrm{N}=119$, First preoperative visit $\mathrm{N}=111$, Last pre-operative visit $\mathrm{N}=111$, Transition to palliative management $\mathrm{N}=25$, and One year after stent placement $\mathrm{N}=17$. 


\section{Supplementary Table 1.}

\section{Reinterventions}

Overall, 31 patients experienced an adverse event that required a reintervention during follow-up until CIS or 1 year if the patient could not undergo CIS.

Symptom was categorized into "Cholangitis," "Biliary obstruction," which included biliary obstructive symptoms and/or abnormal liver function tests without cholangitis, and "Acute cholecystitis."

Cause was categorized into "Ingrowth" for tumor ingrowth into the SEMS, "Overgrowth" for hyperplastic or tumor overgrowth at the edges or extremity of the SEMS, "Migration" for partial distal or proximal migration or complete distal migration of the SEMS, "Presumed CD occlusion" reflecting the theoretical and presumed occlusion by the SEMS of the cystic duct confluence with the common bile duct, "Sludge," which may have been further specified as sludge, necrotic debris, stones, or food impaction (causing succotash cholangitis in reintervention no. 26), "GI Bleed" in one case in setting of SEMS migration without biliary obstruction, and "Kinked SEMS" in one case of an UCSEMS having kinked after placement.

Intervention is self-explanatory. Second SEMS placed is applicable for reinterventions in which a SEMS is exchanged for another SEMS or in which a SEMS is placed inside of a SEMS.

\begin{tabular}{|c|c|c|c|c|c|c|c|c|c|}
\hline $\begin{array}{l}\text { Reinter- } \\
\text { vention } \\
\text { Number }\end{array}$ & Group & $\begin{array}{c}\text { GB in } \\
\text { Situ }\end{array}$ & $\begin{array}{l}\text { SEMS } \\
\text { Length }\end{array}$ & $\begin{array}{l}\text { Days to } \\
\text { reinter- } \\
\text { vention }\end{array}$ & $\begin{array}{c}\text { Days } \\
\text { to CIS }\end{array}$ & Cause & Symptom & Intervention & $\begin{array}{c}\text { Type of } \\
\text { Stent } \\
\text { Placed } \\
\end{array}$ \\
\hline 1 & $\mathrm{UC}$ & Yes & $6 \mathrm{~cm}$ & 195 & NA & Ingrowth & Cholangitis & Biliary RFA & N/A \\
\hline 2 & $\mathrm{UC}$ & Yes & $6 \mathrm{~cm}$ & 168 & NA & Ingrowth & Cholangitis & SEMS in SEMS & $\mathrm{FC}$ \\
\hline 3 & $\mathrm{UC}$ & Yes & $6 \mathrm{~cm}$ & 160 & NA & Ingrowth & Cholangitis & SEMS in SEMS & $\mathrm{FC}$ \\
\hline 4 & $\mathrm{UC}$ & Yes & $6 \mathrm{~cm}$ & 331 & $\mathrm{NA}$ & Ingrowth & Cholangitis & SEMS in SEMS & $\mathrm{FC}$ \\
\hline 5 & $\mathrm{UC}$ & Yes & $6 \mathrm{~cm}$ & 213 & $\mathrm{NA}$ & Ingrowth & Cholangitis & SEMS in SEMS & $\mathrm{FC}$ \\
\hline 6 & $\mathrm{UC}$ & Yes & $4 \mathrm{~cm}$ & 14 & 152 & Ingrowth & Biliary obstruction & SEMS in SEMS & $\mathrm{FC}$ \\
\hline 7 & $\mathrm{UC}$ & Yes & $4 \mathrm{~cm}$ & 42 & NA & Ingrowth & Biliary obstruction & SEMS in SEMS & $\mathrm{FC}$ \\
\hline 8 & $\mathrm{UC}$ & Yes & $4 \mathrm{~cm}$ & 224 & 297 & Ingrowth & Biliary obstruction & SEMS in SEMS & $\mathrm{UC}$ \\
\hline
\end{tabular}




\begin{tabular}{|c|c|c|c|c|c|c|c|c|c|}
\hline 9 & UC & Yes & $4 \mathrm{~cm}$ & 227 & NA & Ingrowth & Biliary obstruction & SEMS in SEMS & $\mathrm{UC}$ \\
\hline 10 & UC & Yes & $4 \mathrm{~cm}$ & 73 & 83 & Ingrowth & Biliary obstruction & PTBD & $\mathrm{N} / \mathrm{A}$ \\
\hline 11 & UC & Yes & $8 \mathrm{~cm}$ & 38 & 60 & $\begin{array}{l}\text { Presumed } \\
\text { CD } \\
\text { occlusion }\end{array}$ & Acute cholecystitis & $\begin{array}{l}\text { Percutaneous } \\
\text { cholecystostomy tube }\end{array}$ & N/A \\
\hline 12 & $\mathrm{UC}$ & Yes & $4 \mathrm{~cm}$ & 24 & $\mathrm{NA}$ & $\begin{array}{l}\text { Presumed } \\
\text { CD } \\
\text { occlusion }\end{array}$ & Acute cholecystitis & $\begin{array}{l}\text { Percutaneous } \\
\text { cholecystostomy tube }\end{array}$ & $\mathrm{N} / \mathrm{A}$ \\
\hline 13 & UC & Yes & $4 \mathrm{~cm}$ & 10 & NA & Sludge & Cholangitis & Sludge removal & $\mathrm{N} / \mathrm{A}$ \\
\hline 14 & UC & Yes & $4 \mathrm{~cm}$ & 203 & NA & Overgrowth & Biliary obstruction & Plastic stent in SEMS & $\mathrm{N} / \mathrm{A}$ \\
\hline 15 & UC & Yes & $6 \mathrm{~cm}$ & 7 & NA & $\begin{array}{l}\text { Kinked } \\
\text { SEMS }\end{array}$ & Cholangitis & SEMS in SEMS & PC \\
\hline 16 & UC & Yes & $4 \mathrm{~cm}$ & 17 & 22 & $\begin{array}{l}\text { No observed } \\
\text { SEMS } \\
\text { occlusion or } \\
\text { migration }\end{array}$ & Cholangitis & Naso-biliary drain & $\mathrm{N} / \mathrm{A}$ \\
\hline 17 & FC & Yes & $6 \mathrm{~cm}$ & 140 & NA & Migration & Cholangitis & SEMS Exchange & $\mathrm{UC}$ \\
\hline 18 & FC & Yes & $4 \mathrm{~cm}$ & 88 & NA & Migration & Cholangitis & SEMS Exchange & $\mathrm{UC}$ \\
\hline 19 & $\mathrm{FC}$ & Yes & $6 \mathrm{~cm}$ & 13 & 63 & Migration & Cholangitis & $\begin{array}{c}\text { FCSEMS removal, } \\
\text { non-study SEMS } \\
\text { placed }\end{array}$ & N/A \\
\hline 20 & $\mathrm{FC}$ & Yes & $6 \mathrm{~cm}$ & 245 & NA & Migration & Biliary obstruction & $\begin{array}{l}\text { FCSEMS removal, } \\
\text { plastic or non-study } \\
\text { SEMS placed }\end{array}$ & $\mathrm{N} / \mathrm{A}$ \\
\hline 21 & FC & Yes & $6 \mathrm{~cm}$ & 204 & NA & Migration & GI Bleed & SEMS Exchange & $\mathrm{UC}$ \\
\hline 22 & $\mathrm{FC}$ & Yes & $6 \mathrm{~cm}$ & 7 & 110 & $\begin{array}{l}\text { Presumed } \\
\text { CD } \\
\text { occlusion }\end{array}$ & Acute cholecystitis & $\begin{array}{l}\text { Percutaneous } \\
\text { cholecystostomy tube }\end{array}$ & N/A \\
\hline 23 & $\mathrm{FC}$ & Yes & $4 \mathrm{~cm}$ & 4 & 118 & $\begin{array}{l}\text { Presumed } \\
\text { CD } \\
\text { occlusion }\end{array}$ & Acute cholecystitis & SEMS Exchange & UC \\
\hline 24 & $\mathrm{FC}$ & Yes & $6 \mathrm{~cm}$ & 53 & $\mathrm{NA}$ & Presumed & Acute cholecystitis & Percutaneous & $\mathrm{N} / \mathrm{A}$ \\
\hline
\end{tabular}




\begin{tabular}{c|c|c|c|c|c|c|c|c|c}
\hline & & & & & $\begin{array}{c}\text { CD } \\
\text { occlusion }\end{array}$ & & cholecystostomy tube \\
\hline 25 & FC & Yes & $6 \mathrm{~cm}$ & 13 & NA & $\begin{array}{c}\text { Presumed } \\
\text { CD } \\
\text { occlusion }\end{array}$ & Acute cholecystitis & $\begin{array}{c}\text { Laparoscopic } \\
\text { cholecystectomy }\end{array}$ & N/A \\
\hline 26 & FC & Yes & $6 \mathrm{~cm}$ & 22 & NA & Sludge & Cholangitis & SEMS Exchange & UC \\
\hline 27 & FC & No & $6 \mathrm{~cm}$ & 147 & NA & Sludge & Cholangitis & SEMS Exchange & UC \\
\hline 28 & FC & Yes & $6 \mathrm{~cm}$ & 168 & NA & Sludge & Cholangitis & $\begin{array}{c}\text { FCSEMS removal, } \\
\text { plastic stent placed }\end{array}$ & N/A \\
\hline 30 & FC & Yes & $4 \mathrm{~cm}$ & 204 & NA & Sludge & Biliary obstruction & SEMS Exchange & UC \\
\hline 31 & FC & Yes & $4 \mathrm{~cm}$ & 276 & NA & Overgrowth & Biliary obstruction & SEMS in SEMS & UC \\
\hline
\end{tabular}

Abbreviations: CD, cystic duct; FC, fully-covered; UC, uncovered; GI, gastrointestinal; N/A, not applicable; RFA, radio frequency ablation; SEMS, selfexpanding metal stent; PC, partially covered; PTBD, percutaneous transhepatic biliary drain 


\section{Abbreviations:}

CIS - curative intent surgery

CSEMS - covered self-expanding metal stents

EUS FNA/FNB - endoscopic ultrasound fine needle aspiration or fine needle biopsy

FCSEMS - fully-covered self-expanding metal stents

ITT - intention-to-treat

LFTs - liver function tests

NATx - neoadjuvant therapy

PD - pancreaticoduodenectomy

PP - per protocol

SEMS - self-expanding metal stents

UCSEMS - uncovered self-expanding metal stents 
Clinical Trial Registration: ClinicalTrials.gov NCT02238847 